\title{
Multimedia Systems
}

Springer-Verlag London Ltd. 
The Springer-Verlag Series on Applied Computing is an advanced series of innovative textbooks that span the full range of topics in applied computing technology.

Books in the series provide a grounding in theoretical concepts in computer science alongside realworld examples of how those concepts can be applied in the development of effective computer systems.

The series should be essential reading for advanced undergraduate and postgraduate students in computing and information systems.

Books in this series are contributed by international specialist researchers and educators in applied computing who draw together the full range of issues in their specialist area into one concise authoritative textbook.

Titles already available:

Deryn Graham and Anthony Barrett

Knowledge-Based Image Processing Systems

3-540-76027-X

Derrick Morris, Gareth Evans, Peter Green, Colin Theaker

Object Orientated Computer Systems Engineering

3-430-76020-2

John Hunt

Java and Object Orientation: An Introduction

3-540-76148-9

David Gray

Introduction to the Formal Design of Real-Time Systems

3-540-76140-3

Mike Holcombe and Florentin Ipate

Correct Systems: Building A Business Process Solution

3-540-76246-9

Jan Noyes and Chris Baber

User-Centred Design of Systems

3-540-76007-5

Arturo Trujillo

Translation Engines: Techniques for Machine Translation

1-85233-057-0

Ulrich Nehmzow

Mobile Robotics: A Practical Introduction

1-85233-173-9

Fabio Paternò

Model-Based Design and Evaluation of Interactive Applications

1-85233-155-0 


\section{Tim Morris}

Multimedia

Systems

Delivering, Generating and Interacting with Multimedia 
Tim Morris, BSc PhD

Department of Computation, UMIST, PO Box 88, Manchester,

M60 1QD, UK

\section{Series Editors}

Professor Ray J. Paul, BSc MSc PhD

Dean of the Faculty of Science, Brunel University, Uxbridge, Middlesex UB8 3PH, UK

Professor Peter J. Thomas, MIEE MBCS CEng FRSA

Centre for Personal Information Management, University of the West of England, Frenchay Campus, Bristol BS16 1QY, UK

Dr Jasna Kuljis, PhD MS Dipl Ing

Department of Information Systems and Computing, Brunel University,

Uxbridge, Middlesex UB8 3PH, UK

\section{ISBN 978-1-85233-248-8}

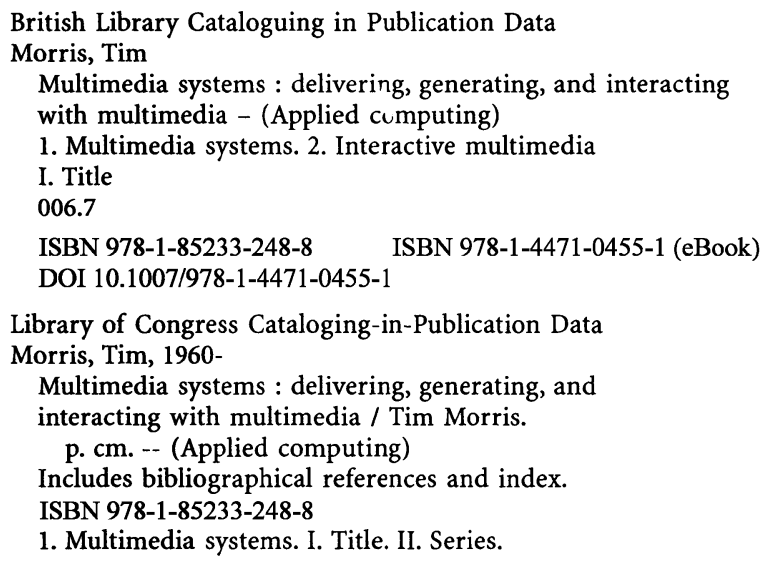

Apart from any fair dealing for the purposes of research or private study, or criticism or review, as permitted under the Copyright, Designs and Patents Act 1988, this publication may only be reproduced, stored or transmitted, in any form or by any means, with the prior permission in writing of the publishers, or in the case of reprographic reproduction in accordance with the terms of licences issued by the Copyright Licensing Agency. Enquiries concerning reproduction outside those terms should be sent to the publishers.

(C) Springer-Verlag London 2000

Originally published by Springer-Verlag London Berlin Heidelberg in 2000

The use of registered names, trademarks etc. in this publication does not imply, even in the absence of a specific statement, that such names are exempt from the relevant laws and regulations and therefore free for general use.

The publisher makes no representation, express or implied, with regard to the accuracy of the information contained in this book and cannot accept any legal responsibility or liability for any errors or omissions that may be made.

Typesetting: Florence Production Ltd, Stoodleigh, Devon

34/3830-543210 Printed on acid-free paper SPIN 10749452 


\section{Preface}

\section{What are Multimedia Systems?}

This book is intended to expose you to multimedia in its widest sense. The popular understanding of this subject is that it is the integration and delivery of text, images and sound, usually on a desktop PC. We are all familiar with examples from the extensive range of multimedia titles available on CD-ROM. These give us a rich set of sensory experiences, and, perhaps more important, we are free to navigate our way through the information as we choose. However, this is only half of the story since these titles can only deliver information.

A recent IEEE publication (Chen, 1997) suggested that multimedia should include all systems that integrate diverse media, in standalone or networked applications, either for presentation or communication. Diverse media implies visual and aural information (text, static and moving pictures and sound). Networking could be realised using intranet or telephone links. Presentation systems would imply the multimedia delivery systems with which we are all familiar. Communication implies a two-way interaction with the computer. So as well as transmitting information, multimedia systems should also be able to understand and react to information presented to them using the same set of diverse media (such as typed text, pictures and sound).

The aims of this book are therefore twofold:

1. to introduce the methods of generating, manipulating and delivering multimedia data;

2. to give an overview of current research that will illustrate what tasks multimedia systems will soon be achieving in the realm of human and computer interaction. 


\section{Multimedia Delivery Systems}

A multimedia delivery system can be any computer system capable of presenting multimedia information. This implies that the computer system has a graphics subsystem that is able to display high resolution images and also has a throughput rate sufficiently high to present moving images on screen. The computer system will also have a sound subsystem whose throughput requirements are less demanding but must nevertheless deliver realistic sound data. At one time this would have meant a computer system with significant hardware additions, at present, an entry-level computer is likely to have these capabilities.

The delivery system must also have some means of receiving input from the operator. Typically this will be via a keyboard or mouse, but voice input is becoming more common.

The delivery system will be of limited use without data to deliver and the software to drive it. The archetype example is the CD-ROM. A CD may contain a game, an encyclopaedia, a travel guide or any other data, plus the software to browse that data. More esoteric examples can be found. A national chain of supermarkets has a computer system with which customers are able to browse a small database of recipes and vouchers. A local transport authority has a publicly accessible information booth that provides data regarding bus routes and timetables. Systems such as these two have very different hardware requirements to a computer system that is to sit on a desk in the home, classroom or office. But these systems also have the same delivery characteristics as a desktop system: the user has some control over what data he is presented and how he is able to navigate through the available information.

\section{Multimedia Interactivity}

All multimedia systems are interactive to a certain, limited, degree. If this were not so then we would be unable to navigate a path through the data. However, the currently available multimedia systems have extremely limited channels of interactivity. Typically, we may use the mouse, keyboard or perhaps voice input to control the system. The systems themselves are also limited, the majority being desktop PCs, with some exceptions. A major strand in this book will be to examine novel multimedia interactions. The single outstanding characteristic of these systems is that they allow communication from the computer user to the computer to be via any more natural channel that the mouse or keyboard. This could be using voice control, using gestures, by the computer "reading" sign language or lips. Example systems are being developed by most major hardware and software manufacturing corporations, whether this is to control domestic appliances, to simplify office work patterns or to deliver information on the shop floor. 
The look and feel of the computer is also changing. If the aim of developing multimedia interactivity is to facilitate human/computer interaction, then the computer can be removed from the desktop and there may be no need for a mouse or keyboard, or perhaps even the screen. Ultimately, using the multimedia computer will seem as natural as talking to a friend.

\section{Course Background}

This book was developed for a single semester course of the same name given to advanced undergraduate and postgraduate students in the Department of Computation at UMIST. None of the students who attend the course has had any previous exposure to courses dealing with multimedia systems. Although some students have attended modules dealing with computer vision, computer graphics or speech understanding, these are not prerequisites for the course which is entirely self contained.

The course has been delivered using a mixture of formal lectures, tutorials and assessed exercises over a period of 12 weeks. Some of the students attending the course have a stronger background in mathematics than others. Rather than exclude any because of their prior knowledge, the specialist topics required by the course are presented in appendices.

\section{The Book's Organisation}

My intention in this book is to do more than equip students to design multimedia delivery systems. I also intend to outline what multimedia computers could be doing five years from now. Therefore the book is divided into two parts. Part I (Chapters 2 to 4 ) will discuss how multimedia delivery systems are designed and constructed. The description is necessarily brief and the interested reader is referred to more specialist books on each topic. Part II (Chapters 5 to 11) will discuss methods of realising true multimedia computing; hence the book's subtitle: generating and interacting with multimedia.

Part I starts with an examination of human perception and data coding (see Chapter 1). The rationale for this is that if we are to present information in a pleasing and realistic fashion, then we ought to be able to specify what pleasing and realistic actually mean. In perceptual terms, this implies that we must examine the typical human's ability to see images and video and to hear sound to find what is the resolution of our visual and aural systems. This then dictates the resolution we must have for the images, videos and sounds that our multimedia systems must deliver if they are to look realistic. Methods of storing these objects are also examined. 
The next chapter presents an examination of the methods with which multimedia delivery systems are assembled. How is the raw data organised and how is the reader's path through the data facilitated? The first half of the book concludes with an examination of the hardware used in multimedia systems, what are the requirements of a multimedia computer and what peripheral devices are required to capture, manipulate and present multimedia data. The typical multimedia computer is presented, along with alternatives and their areas of application.

The second half of the book examines a number of topics, most of which are still based in the laboratory, some of which are beginning to appear as commercial products. These are perceptual interfaces. They include systems able to understand human speech, systems able to synthesise speech, systems able to observe the user's eyes and interpret direction of gaze as a command to move the cursor, systems able to recognise and interpret gestures made by the user and systems able to respond to completely unconstrained input. In short, the input to these systems is via any channel other than the keyboard or mouse. A chapter is devoted to each topic. The penultimate chapter is concerned with the generation of visual feedback. In the same way as speech synthesis was examined as a method of providing aural feedback, visual feedback is necessary is particular systems.

The book has several appendices that contain information that is useful but not directly relevant to the course. An overview of HTML (hypertext mark-up language) is presented. This is useful as it is a vehicle for presenting multimedia systems and has been used by students following the course in designing websites as an assessed exercise. The overview is necessarily brief and the reader must be referred to other texts for a more complete description. All of the specialist mathematical techniques are described in a second appendix. Finally, a discussion of some publicly available software is given, this is restricted to relevant software that will manipulate images, sounds and video sequences.

\section{Supplementary Materials}

The text is supplemented by information available on an associated website: www.co.umist.ac.uk/ dtm/software.html. This material includes transparencies and source material used in assessments.

\section{Bibliography}

Tsuhan Chen (1997) The past, present and future of multimedia signal processing. IEEE Signal Processing 14. 


\section{Contents}

1 Introduction ............................ 1

What are Multimedia Systems? .................. 1

Multimedia Delivery Systems .................. 4

Multimedia Interactivity ................... 5

What Topics does the Book Cover? ............... 6

Bibliography ......................... 6

\section{Part I}

2 Perception and Data Coding .................. 9

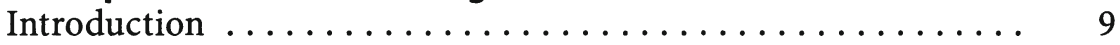

Perception of Multimedia Data ................ 9

perception of Sound ..................... 10

Perception of Static Image Data $\ldots \ldots \ldots \ldots \ldots \ldots \ldots \ldots . \ldots \ldots$

Perception of Moving Image Data $\ldots \ldots \ldots \ldots \ldots \ldots \ldots . \quad 15$

Capture of Multimedia Data .................... 16

Capturing Sound ....................... 17

Capturing Static Image Data ................... 19

Capturing Video Data ...................... 22

Coding Multimedia Data ................... 24

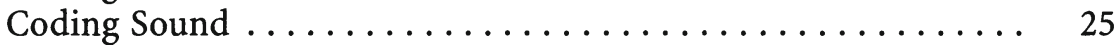

Coding Still Images $\ldots \ldots \ldots \ldots \ldots \ldots \ldots \ldots \ldots \ldots \ldots . \ldots \ldots$

Coding Video Data ....................... 29

Coding/Decoding Hardware .................. 31

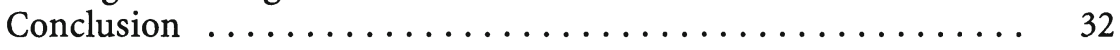

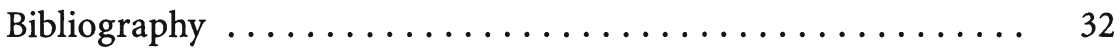

3 Organising and Delivering Multimedia Objects ........ 33

Introduction $\ldots \ldots \ldots \ldots \ldots \ldots \ldots \ldots \ldots \ldots \ldots \ldots \ldots$

A Classification of Multimedia Presentations ........... 34

What is Required of a Multimedia Presentation Design Tool? ... 37

Characteristics of Practical Design Tools ............. 38

Implementing Multimedia Presentations Using HTML . . . . . 39

Good Design Pratice ....................... 41

Manipulating Multimedia Content $\ldots \ldots \ldots \ldots \ldots \ldots \ldots, 41$

Conclusion .......................... 45

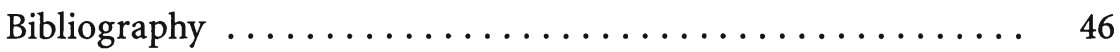


4 Hardware to Support Multimedia Systems ........... 47

Introduction $\ldots \ldots \ldots \ldots \ldots \ldots \ldots \ldots \ldots \ldots, 47$

The Multimedia PC ..................... 48

Peripheral Devices ....................... 49

Kiosk Systems ........................... 55

Conclusions .......................... 57

Bibliography $\ldots \ldots \ldots \ldots \ldots \ldots \ldots \ldots \ldots \ldots \ldots \ldots \ldots \ldots$

\section{Part II}

5 Multimedia Interactivity $\ldots \ldots \ldots \ldots \ldots \ldots \ldots \ldots \ldots, 61$

Introduction .......................... 61

The Future of Multimedia Communication Systems ....... 62

Theoretical Foundations ................... 67

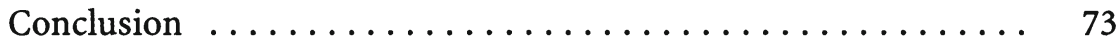

Bibliography $\ldots \ldots \ldots \ldots \ldots \ldots \ldots \ldots \ldots \ldots \ldots \ldots \ldots \ldots \ldots$

6 Speech Generation $. . \ldots \ldots \ldots \ldots \ldots \ldots \ldots \ldots . \ldots . \ldots 75$

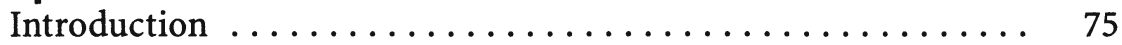

Physiology ............................... 76

Historical Speech Generating Machines . . . . . . . . . 79

Synthesis from Stored Segments . . . . . . . . . . . . 81

Synthesis from Rules ..................... 82

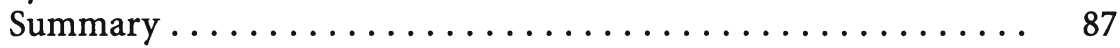

Bibliography $\ldots \ldots \ldots \ldots \ldots \ldots \ldots \ldots \ldots \ldots \ldots .88$

7 Speech Recognition $\ldots \ldots \ldots \ldots \ldots \ldots \ldots \ldots \ldots \ldots \ldots . . \ldots 9$

Introduction ......................... 89

Principles Underlying Speech Recognition ............ 90

Architecture of a Speech Recognition System ........... 92

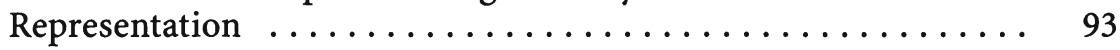

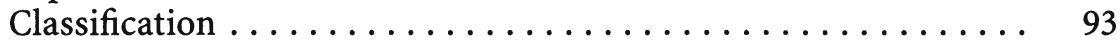

Recognition ........................... 95

Summary .......................... 99

Bibliography ........................ 100

8 Head Pointing Devices $\ldots \ldots \ldots \ldots \ldots \ldots \ldots \ldots \ldots \ldots . \ldots 1$

What is a Head Pointing Device? .................. 101

Where Would Head Pointing Device Be Used? . . . . . . . . . 102

The Video Based Head Pointing Device: Hardware . . . . . . . . 103

Possible Software Solutions . . . . . . . . . . . . . . . 107

Conclusions .............................. 119

Bibliography ....................... 120 
9 Gesture Recognition ........................ 121

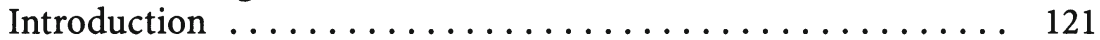

Example Systems . . . . . . . . . . . . . . . . . . 122

Requirements ........................ 127

Identifying and Describing Hands and Fingers in Video

Sequences ........................... 127

Tracking Hands and Fingers in Video Sequences ......... 132

Representing Gestures .................... 133

Recognising Gestures ..................... 134

Summary and Conclusions ................. 134

Bibliography ........................ 135

10 Motion Following and Interpretation $\ldots \ldots \ldots \ldots \ldots . . \ldots 137$

Introduction ......................... 137

Activity Understanding Systems . . . . . . . . . . . . 138

Information Delivery Systems .................. 143

Video Surveillance and Monitoring $\ldots \ldots \ldots \ldots \ldots \ldots \ldots .146$

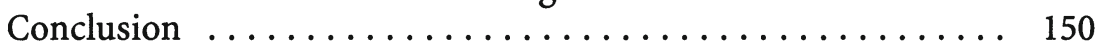

Bibliography ........................ 150

11 Synthesising a Visual Response $\ldots \ldots \ldots \ldots \ldots \ldots \ldots . \ldots 153$

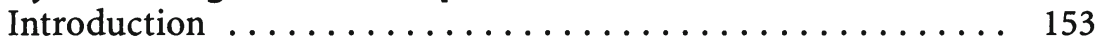

Feedback ............................. 153

An Overview of Methods of Generating and Animating

Head Models ............................ 155

Facial Animation Systems . . . . . . . . . . . . . . . 160

Conclusions ............................ 161

Bibliography ........................ 162

Conclusions .............................. 163

The Current State of Multimedia Systems . . . . . . . . 163

What of the Future? .................... 165

Appendices ............................... 167

HTML - Hypertext Markup Language . . . . . . . . . . 167

Mathematical Techniques ..................... 179

Publicly Available Software . . . . . . . . . . . . . . . 185

Index $\ldots \ldots \ldots \ldots \ldots \ldots \ldots \ldots \ldots \ldots \ldots \ldots \ldots \ldots \ldots . \ldots \ldots$ 